\title{
Development and sensory evaluation of safed musli (Chlorophytum borivilianum) nutritional gummies for stunted child
}

\author{
Anum Nazir ${ }^{1,2^{*}}$, Nizwa Itrat ${ }^{1,2}$, Duaa Munawar ${ }^{1}$ and Muhammad Awais \\ Saleem $^{2}$ \\ 1. Department of Nutrition and Dietetics, the University of Faisalabad, Punjab, Pakistan \\ 2. Department of Nutritional Science, Government College University Faisalabad Punjab, Pakistan \\ *Corresponding author's email: Anum.Nazir@tuf.edu.pk \\ Citation \\ Anum Nazir, Nizwa Itrat, Duaa Munawar and Muhammad Awais Saleem. Development and sensory evaluation of \\ safed musli (Chlorophytum borivilianum) nutritional gummies for stunted child. Pure and Applied Biology. Vol. 11, \\ Issue 3, pp806-813. http://dx.doi.org/10.19045/bspab.2022.110081
}

\begin{tabular}{llll}
\hline \hline Received: 20/08/2021 & Revised: 30/10/2021 & Accepted: 11/11/2021 & Online First: 07/12/2021 \\
\hline
\end{tabular}

\section{Abstract}

Chlorophytum borivilianum, often known as 'Safed Musli,' is a rare traditional medicinal herb with nutritional, medicinal, and therapeutic properties. Safed Musli is well-known for its excellent nutritional content. It is used to treat physical illness and weakness, as an aphrodisiac and revitalizer, as a general sex tonic, as a cure for diabetes, arthritis, and increasing body immunity, as a cure for natal and postnatal problems, for rheumatism and joint pains, to increase lactation in nursing mothers, as an antimicrobial, anti-inflammatory, and antitumor agent, and it is also used to treat diarrhea, dysentery. The current study was designed to evaluate the nutritional benefit of safed musli gummies, specifically for stunted children from low-income families. The proximate study also lends support to the creation of safed musli gummies to improve children's nutritional status. The data was subjected to statistical analysis. Data reveled that safed musli gummies were high in nutrition content. The proximate analysis also supports the development of safed musli gummies due to its nutritional benefits. The safed musli powder was incorporated in gummies by using different concentrations $(\mathrm{T} 1=5, \mathrm{~T} 2=10, \mathrm{~T} 3=15, \mathrm{~T} 4=20, \mathrm{~T} 4=25, \mathrm{~T} 5=30 \mathrm{~g})$. According to the results, safed musli powder are a good source of nutrition for stunted growth children and this could be a vital approach for combating malnourished children.

Keywords: Micronutrient malnutrition; Stunted children; Safed musli; Gummies

\section{Introduction}

The Food and Agriculture Organization [1], starvation is the primary cause of more than $50 \%$ of the annual deaths of an estimated 12 million children under the age of 5 years. Malnutrition is also considered to play the leading role in the sprouting of poverty in children who survive, producing a weakened health status [2] and eternal physical and mental growth harm. In fact, infants are more vulnerable to the symptoms of malnutrition at the time of supplemental feeding [3]. This is because, in the supply of supplementary ingredients, the need for macro and micronutrients is not met. A low concentration of nutrients in some of the supplemental foods can also contribute to a child's undernourishment [4]. 
Malnutrition is an increasing impairment to human well-being. The prevalence of malnutrition in both children and women in Pakistan is far higher. It is blamed for secret gaps in the state's economic growth. Child nutrition is still known to be a significant cause of children's disease and mortality, leading to around $50 \%$ of the world's child deaths. Of the main dietary complications, protein energy deficiency (PEM) has a serious effect on the masses. 9.6 million children under five are malnourished in Pakistan. Although 45 percent of adolescents in Pakistan are stunted, according to the Global Nutrition Report (2016).

Children with extreme malnutrition are particularly susceptible to significant, secondary immunodeficiency infections. Indeed, rather than the prevalence of malnutrition itself, the involvement of children with extreme malnutrition in medical care may be attributable to a serious infection. Immunological dysfunction in malnourished persons might be caused by a number of factors. Malnourished children typically have decreased skin, respiratory, and gastrointestinal mucosal barrier reliability. It can lead to significant health problems such as stunted growth, vision problems, heart disease, and diabetes.

Chlorophytum borivilianum, often known as 'Safed musli,' is a major medicinal herb that is utilised in many Ayurvedic vital tonics and aphrodisiac preparations [5]. Chlorophytum borivilianum is a herb from tropical wet forests in peninsular India with lanceolate leaves. Safed Musli is the generic name (also commonly known as musli). In certain countries, it is cultivated and consumed as a leaf vegetable, and its roots are used under the name healthy musli as a health tonic [6]. There are several probable reasons of immunological dysfunction in malnourished people. Skin, respiratory, and gastrointestinal mucosal barrier reliability is frequently impaired in malnourished children. It can cause serious health issues such as stunted development, eye difficulties, heart disease, and diabetes. Jellies and gummies can be separated between two confections in this group based on the kind of gelling agent employed, utilising gelatin and other hydrocolloids such as pectin, respectively [7]. The usefulness is impaired due to food additives and increased sugar contents, as well as the non-required/desired chemicals created by heat application.

An herbaceous plant with a condensed stem disc, known as Safed mosli (Chlorophytum borivilianum), from which a swirl of leaves emerged. The leaves of this plant are sessile and measure 10-40 $\mathrm{cm}$ in length and 0.6-4.0 $\mathrm{cm}$ in width. Safed musli is a tiny annual plant that thrives in tropical and subtropical regions at elevations of up to $1500 \mathrm{~m}$ [8]. It may reach a maximum height of 1.5 feet. Its tubers (roots) can spread to a depth of 10 inches. It includes over 25 alkaloids, including carbohydrates, antioxidants, fats, saponins, hormones, magnesium, potassium, calcium, resins, phenol, polysaccharides and mucilage, as well as a rich supply of several other critical components. It also contains a significant variety of basic sugars, most of which are sucrose, fructose, mannose, glucose, xylose and galactose [9].

It is believed that Safed musli or chlorophytum is a medicinal herb, usually with white and small flowers, arising from sparse panicles and up to $120 \mathrm{~cm}$ long [5]. Because of its value as an important aphrodisiac agent for medicinal use, it is commercially approved and grown in most regions around the world [10]. As an ingredient, it has a remarkable role in various ayurvedic formulas due to incomparable medicinal and therapeutic characteristics. Not only is it relevant because of its acceptability as a health tonic, but it has also gained prominence as a booster of the general immune system of the body [11]. The Medicinal Plants Board acknowledges this as 
the sixth most significant herbaceous plant with diversified medicinal properties [6].

The habit of using natural goods is increasingly growing. In most industrialised nations, there has been systematic surveillance of the use of herbal medicines and medicinal plants as a normative framework for sustaining good health. Increasing reliance in developed communities on the usage of medicinal plants has also been linked to the production of many medicines and chemotherapeutics, both from plant species and from commonly used rural herbal preparations [12]. In the treatment of mild diseases, herbal medicines have gained even more success, leading to growing knowledge of personal wellbeing preservation by natural products [13]. Indeed, the competition and public interest have become so strong that many medicinal plants have an immense chance of extinction and, obviously, of genetic diversity being destroyed [14]. The global move towards herbal preparations over synthetic pharmaceuticals has now become aware of the value of concentrated studies in medicinal plants. The Indian continent is home to a diverse range of medicinal plants, the majority of which may be found as wild plants in the forests of hills and plains [12]. Disruptions to the natural ecosystems of these plants as a result of anthropogenic behaviour and the introduction of invasive species have resulted in a dramatic reduction in the population of these valuable plant species, and many of these species are now classified as uncommon, critically rare, or endangered [15]. Also known as Safed Musli, Chlorophytum borivilianum Santapau and Fernandez is a common medicinal plant of assorted Ayurvedic value. It is used therapeutically in the Ayurvedic method of medicine [16]. Generally speaking, raising general body immunity is considered very healthy. Its aphrodisiac effects have shown to be very useful for erectile dysfunction sufferers and to improve male potency [14]. As they are high in glycosides, they have spermatogenic properties and are effective in treating impotence. Its roots are commonly used in the Ayurvedic and Unani systems of medicine for different medicinal applications. It is understood that certain physical illnesses and weaknesses can be healed [6]. Diabetes, arthritis and increased general body immunity are now confirmed to be healed. The oligosaccharide chain is typically bound at position C3 (monodesmosidic), but certain saponins at positions C26 or C28 have an extra sugar moiety (bidesmosidic). The major objective was to develop a cost-effective and nutritional enrich product to overcome stunted growth as compared with other costly supplements especially for poor people in developing countries, and to determine the proximate analysis of safed musli.

\section{Materials and Methods}

An experiment was planned at The University of Faisalabad to determine the effect of safed musli gummies on the nutrition of stunted grown children. The experiment consists of six treatments with various levels of safed musli along with a control treatment (Table 1). The key elements, i.e., Safed Musli were collected from pancari.pk online stores in Pakistan. Safed Musli was ground into flour. To minimise fragmentation and contamination, flour was packaged in a polyethene bag and kept at room temperature until needed. Proximate analysis was performed in accordance with AOAC guidelines [17]. The moisture content was calculated according to the 43-15A process as alluded to in the AOAC [17]. The ash content was measured in compliance with the $43-15 \mathrm{~A}$ process as alluded to in the AOAC [17]. After the samples were dried at $550^{\circ} \mathrm{C}$ for about 4.55.5 hours, white ash was collected. The method of charring was also done to make the sample smoke free before the samples were 
put in the muffle furnace. The ash content was measured in compliance with the 43-15A process as alluded to in the AOAC [17]. After the samples were dried at 550 ?? $\mathrm{C}$ for about 4.5-5.5 hours, white ash was collected. Mazzeo et al. [18] described the process of color determination of all treatments using a hand held colorimeter according to the Mazzeo method previously described (Tristimulu,s Colorimeter). All samples were determined according to the Textural Procedure (TA-XT2, Stable Microsystems, Surrey, UK) as defined by [19]. In the phase of product development, the gummies with various levels of safed musli flour was prepared. (safed musli $0-30 \%$ and $0-30 \mathrm{~g}$ ). The sensory assessment of safed musli gummies was conducted under bright white light at room temperature. The freshly prepared safed musli gummies were put on clean white boxes and numbered on the appraisal day accordingly. During the judgmental process, the panellists were given the appropriate utensils, napkins and water for rinsing. The gummies were introduced in a succession, and the panellists were asked to assess the gummies with varied treatments for all of the specified parameters. The 9point hedonic scale testing method was used for assessing sensory attributes such as look, taste, colour, flavour, texture, and overall attractiveness. Finally, to assess the importance of the findings obtained for each parameter. Steel et al. [20] reported the statistical analyses utilised.

Table 1. Treatment plan with various level of safed musli

\begin{tabular}{|c|c|c|}
\hline Treatments & $\begin{array}{c}\text { Percentage of Safed musli } \\
\text { gummies }\end{array}$ & $\begin{array}{c}\text { Quantity of Safed musli } \\
\text { gummies }\end{array}$ \\
\hline $\mathbf{T}_{\mathbf{~}}$ & $0 \%$ & $0 \mathrm{~g}$ \\
\hline $\mathbf{T}_{\mathbf{1}}$ & $5 \%$ & $5 \mathrm{~g}$ \\
\hline $\mathbf{T}_{\mathbf{2}}$ & $10 \%$ & $10 \mathrm{~g}$ \\
\hline $\mathbf{T}_{\mathbf{3}}$ & $15 \%$ & $15 \mathrm{~g}$ \\
\hline $\mathbf{T}_{\mathbf{4}}$ & $20 \%$ & $20 \mathrm{~g}$ \\
\hline $\mathbf{T}_{\mathbf{5}}$ & $25 \%$ & $25 \mathrm{~g}$ \\
\hline $\mathbf{T}_{\mathbf{6}}$ & $30 \%$ & $30 \mathrm{~g}$ \\
\hline
\end{tabular}

\section{Results}

Malnutrition mostly affects children under the age of five in low- and middle-income countries, and it involves stunting, wasting, and kwashiorkor, sometimes known as severe acute malnutrition with severe wasting and kwashiorkor. We use the term'severe malnutrition'here to properly illustrate the contributions of extreme hunger, insufficient housing standards with widespread health and hygiene deficiencies, a high prevalence of infectious diseases and environmental crimes, food shortages, poor maternal and foetal nutritional status, and suboptimal nutritional intake in infancy. Children who are extremely malnourished, often as a result of acute infectious diseases, are at an increased risk of death.

Proximate analysis is an essential criterion for categorising the nutritional content of food [21]. As a result, the stability of foods is dependent on their proximate composition in terms of processing and storage, thus the sample of Safed musli was subjected to several analytical procedures for the examination of their moisture ash, crude protein, crude fibre, and crude fat. Sensory analysis is a study field that applies laboratory design and quantitative analysis principles to the use of human senses in order to analyse consumer goods. For discipline, panels of human assessors who evaluate the 
items and document their replies are required (Fig. 1).

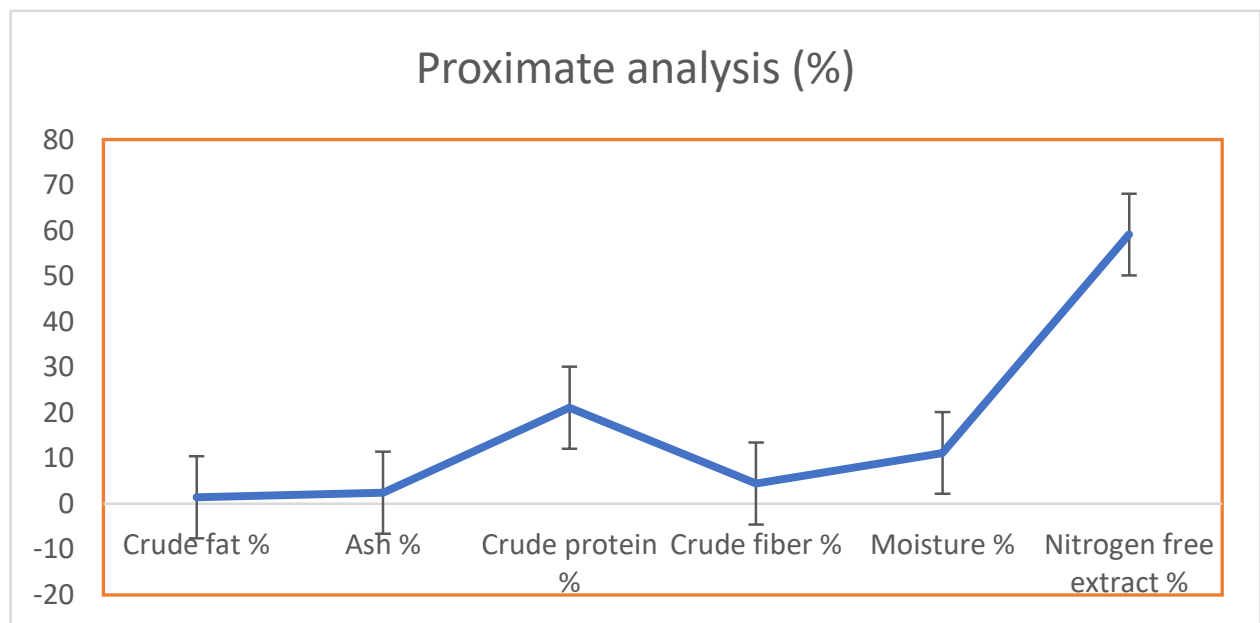

Figure 1. Proximate analysis of safed musli

A trained panel evaluated Safed muslifortified gummies (T0, T1, T2, T3, T4, T5, T6) for look, taste, colour, flavour, texture, and overall acceptability using a 9hedonic scale. Any paint, pigment, or chemical that adds colour to food or drink is referred to as a food colourant or colour additive. They are available in a number of forms, such as oils, powders, gels, and pastes. Food colouring is used in both commercial food processing and home cookery. 7.430 .85 is the total colour perception. T3, T4, and T6 fared the best in terms of colour characteristics when compared to the control. The significance level is less than 0.05, indicating that the results are significant. Flavors' major purpose is to spice up dishes because they have no nutritive qualities. Flavors come in both chemical and natural forms. Natural flavours also require a lift. A minimal quantity of synthetic compounds is often used in mixtures to produce these blends of flavours. The overall flavour content is $7.34 \pm 0.9$. According to flavour, all treatments attained good score than $\mathrm{T} 1$ (Fig. 2).

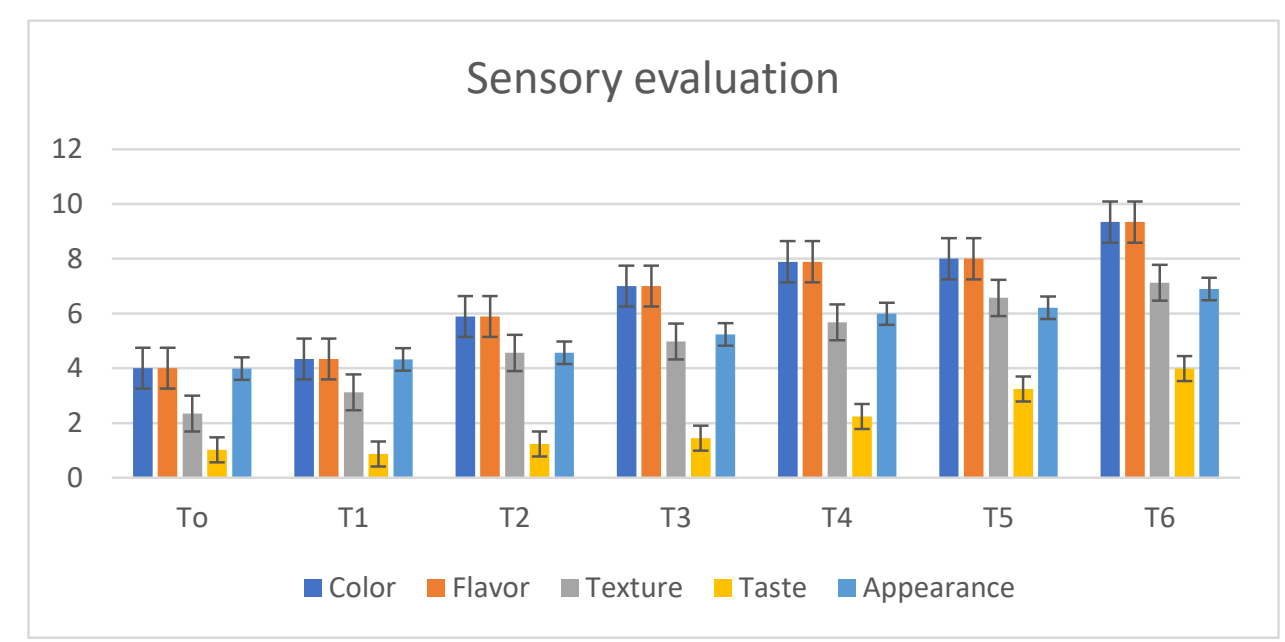

Figure 2. Sensory evaluation 
The point of significane is less than 0.05 so the results are significant. The texture of food is characterised as those properties of a food that are perceived in the mouth and hands by touch. To explain food texture, we use several terms. Foods may be fluffy or rough, mushy or crunchy, or smooth or lumpy. For the pleasure and acceptability of foods, texture is essential. The overall texture evaluation is $7.53 \pm 1.04 \%$. The texture of $\mathrm{T} 1$, $\mathrm{T} 2$ and $\mathrm{T} 3$ scored lowest then $\mathrm{T} 5$ and T6. The point of significane is less than 0.05 so the results are significant.

The (Table 2) depicts the proximate features of various levels of safed musli (0-30g) and results revealed that maximum moisture content (44.29\%), maximum ash content $(1.20 \%)$, maximum protein $(1.10 \%)$ and maximum fiber $(3.20 \%)$ was found in treatment where maximum safed musli was added (Table 2). The results showed that with the increase in safed musli proximate features were also increased.

Table 2. Proximate analysis of safed musli at different levels of safed musli

\begin{tabular}{|c|c|c|c|c|}
\hline Treatment & Moisture \% & Ash (\%) & Protein \% & Fiber \% \\
\hline $\mathrm{T}_{0}$ & $86.43 \pm 2.02^{\mathrm{b}}$ & $1.09 \pm 0.01^{\mathrm{ab}}$ & $0.93 \pm 0.11^{\mathrm{b}}$ & $2.43 \pm 0.42^{\mathrm{ab}}$ \\
\hline $\mathrm{T}_{1}$ & $89.28 \pm 2.26^{\mathrm{ab}}$ & $0.96 \pm 0.01^{\mathrm{d}}$ & $0.92 \pm 0.01^{\mathrm{b}}$ & $1.76 \pm 0.19^{\mathrm{b}}$ \\
\hline $\mathrm{T}_{2}$ & $90.74 \pm 2.44^{\mathrm{a}}$ & $0.90 \pm 0.03^{\mathrm{cd}}$ & $0.91 \pm 0.01^{\mathrm{b}}$ & $1.74 \pm 0.06^{\mathrm{b}}$ \\
\hline $\mathrm{T}_{3}$ & $87.92 \pm 2.61^{\mathrm{ab}}$ & $1.04 \pm 0.04^{\mathrm{bc}}$ & $0.92 \pm 0.01^{\mathrm{b}}$ & $2.28 \pm 0.48^{\mathrm{ab}}$ \\
\hline $\mathrm{T}_{4}$ & $89.10 \pm 1.14^{\mathrm{ab}}$ & $0.97 \pm 0.02^{\mathrm{cd}}$ & $0.90 \pm 0.02^{\mathrm{b}}$ & $2.23 \pm 0.44^{\mathrm{ab}}$ \\
\hline $\mathrm{T}_{4}$ & $63.43 \pm 2.73^{\mathrm{c}}$ & $1.13 \pm 0.09^{\mathrm{e}}$ & $0.98 \pm 0.06^{\mathrm{ab}}$ & $2.94 \pm 0.04^{\mathrm{a}}$ \\
\hline $\mathrm{T}_{6}$ & $44.29 \pm 2.71^{\mathrm{d}}$ & $1.20 \pm 0.08^{\mathrm{f}}$ & $1.10 \pm 0.09^{\mathrm{a}}$ & $3.20 \pm 0.1^{\mathrm{a}}$ \\
\hline
\end{tabular}

\section{Discussion}

Starvation is the primary cause of more than $50 \%$ of the annual deaths of an estimated 12 million children under the age of 5 years. Malnutrition is also considered to play the leading role in the sprouting of poverty in children who survive, producing a weakened health status [2] and eternal physical and mental growth harm. In fact, infants are more vulnerable to the symptoms of malnutrition at the time of supplemental feeding [3]. This is because, in the supply of supplementary ingredients, the need for macro and micronutrients is not met. A low concentration of nutrients in some of the supplemental foods can also contribute to a child's undernourishment [4].

Malnutrition mostly affects children under the age of five in low- and middle-income countries, and it involves stunting, wasting, and kwashiorkor, sometimes known as severe acute malnutrition with severe wasting and kwashiorkor. We use the term'severe malnutrition' here to properly illustrate the contributions of extreme hunger, insufficient housing standards with widespread health and hygiene deficiencies, a high prevalence of infectious diseases and environmental crimes, food shortages, poor maternal and foetal nutritional status, and suboptimal nutritional intake in infancy and early childhood. Children who are extremely malnourished, often as a result of acute infectious diseases, are at a higher risk of serious illness and death [22].

\section{Conclusion}

Safed musli is a decent source of nutrients, making it a potential source for exploring and adding value to various foods such as gummies used to cope with micronutrient malnutrition. Owing to its appealing color and enhanced nutritional value, Safed musli powder improved the color and acceptability of gummies. Safed musli supplementation, as literature showed, had a greater effect on human nutrition than inorganic nitrate. Finally, it could be concluded that Safed musli powder is a good source of carbohydrates, fiber and protein, fiber is good for blood pressure reduction that reduces the 
risk of CVD and other heart problems. In the form of gummies, Safed Musli is a critical and most cost-effective source of nutrition for stunted children.

\section{Authors' contributions}

Conceived and designed the experiments: A Nazir \& N Itrat, Performed the experiments: D Munawar, Analyzed the data: MA Saleem, Contributed materials/ analysis/ tools: A Nazir, Wrote the paper: N Itrat \& A Nazir.

\section{References}

1. Food and Agricultural Organization (FAO) (2012). Globally almost 870 Million Chronically UndernourishedNew Hunger Report.

2. Algur V, Yadavannavar MC \& Patil SS (2012) Assessment of nutritional status of under five children in urban field practice area. Int J Curr Res Rev 4: 122-126.

3. Park K (2013). Preventive and Social Medicine (22nd Edn.). Banarasidas Bhanot Publishers pp. 508-836. 4.

4. De Pee S \& Bloem MW (2009). Current and potential role of specially formulated foods and food supplements for preventing malnutrition among 6-to 23month-old children and for treating moderate malnutrition among 6-to 59month-old children. Food and Nut Bull 30(3 Suppl3): S434-S463.

5. Khanam Z, Singh O, Singh R \& Bhat IUH (2013). Safed musli (Chlorophytum borivilianum): A review of its botany, ethnopharmacology and phytochemistry. $J$ of Ethnopharmacol 150(2): 421-441.

6. Thakur M, Paul C, Myrna A, Carol M \& Vinod K (2011). Immunomodulatory polysaccharide from Chlorophytum borivilianum roots Hindawi Publishing Corporation Evidence-Based Complementary and Alternative Medicine Volume. pp. 105-106.

7. Haque $R$ \& Bera $T$ (2011). Peer Reviewed Literature on medicinal activity of Chlorophytum borivilianum
Commercial Medicinal Plant. Int J Drug Dev \& Res 3(1): 116-1130.

8. Hani NM, Romli SR, Ahmad M (2015). Influences of red pitaya fruit puree and gelling agents on the physico-mechanical properties and quality changes of gummy confections. Int J Food Sci Technol 50: 331-339.

9. Onofiok NO \& Nnanyelugo DO (2012). Weaning Foods in West Africa: Nutritional Problems and Possible Solutions. Food Nutri Bull 19.

10. Farnsworth NR \& Soejarto DD (1991). Global importance of medicinal plants. The Conser of Med Plants 26: 2551.

11. Cabrera-Perez J, Condotta SA, Badovinac VP \& Griffith TS (2014). Impact of sepsis on CD4 $\mathrm{T}$ cell immunity. $J$ of Leukocyte Biol 96(5): 767-777.

12. Okigbo RN, Eme UE \& Ogbogu, S (2008). Biodiversity and conservation of medicinal and aromatic plants in Africa. Biotechnol and Mol Biol Rev 3(6): 127-134.

13. Del Prete A, Scalera A, Iadevaia MD, Miranda A, Zulli C, Gaeta L, Tuccillo C, Federico A \& Loguercio C (2012). Herbal products: benefits, limits, and applications in chronic liver disease. Evidence-Based Complementary and Alternative Medicine.

14. Hamilton AC (2004). Medicinal plants, conservation and livelihoods. Biodiver \& Conser 13(8):1477-1517.

15. Goulson D (2003). Effects of introduced bees on native ecosystems. Ann Rev of Ecol, Evolu and Syst 34(1): 1-26.

16. Maiti S \& Geetha KA (2005). Characterization, genetic improvement and cultivation of Chlorophytum borivilianum--an important medicinal plant of India. Plant Genetic Resou 3(2): 264. 
17. AOAC (2006). Official Methods of Analysis. 18th Edition, Association of Official Analytical Chemists, Gaithersburgs, MD.

18. Mazzeo T, Paciulli M, Chiavaro E, Visconti A, Fogliano V, Ganino $\mathrm{T}$ \& Pellegrini N (2015). Impact of the industrial freezing process on selected vegetables -Part II. Colour and bioactive compounds. J Food Res Inter 75: 89-97.

19. Huang F, Long Y, Liang Q, Purushotham B, Swamy MK \& Duan Y (2019). Safed Musli (Chlorophytum borivilianum L.) callus-mediated biosynthesis of silver nanoparticles and evaluation of their antimicrobial activity and cytotoxicity against human colon cancer cells. $J$ of Nanomaterials.
20. Steel RGD, Torrie JH \& Dicky DA (1997) Principles and Procedures of Statistics, A Biometrical Approach. 3rd Edition, McGraw Hill, Inc Book Co, New York. pp. 352-358.

21. Bathoju G, Rao K \& Giri A (2017). Production of sapogenins (stigmasterol and hecogenin) from genetically transformed hairy root cultures of Chlorophytum borivilianum (Safed musli). Plant Cell, Tissue and Organ Culture (PCTOC) 131(3): 369-376.

22. Meena RP \& Kadam VA (2021). Characterization of Macrophomina phaseolina associated with leaf blight disease on Chlorophytum borivilianum Santapau \& RR Fern. and its fungicidal susceptibility. $J$ of Appl Res on Med and Aromatic Plants 20: 100288. 